\title{
O sistema único de saúde brasileiro: em busca de uma identidade
}

\author{
Sérgio Arthur Silva ${ }^{1}$ Bruna Parnov Machado ${ }^{1}$ Suzinara Beatriz Soares de Lima ${ }^{2}$
}

\begin{abstract}
RESUMO
Criado em plena época de transição, no fim do regime de ditadura militar e início do processo de restabelecimento do Estado Democrático e de Direito, o Sistema Único de Saúde (SUS) surge como uma conquista popular, que teve como embrião o Movimento da Reforma Sanitária e a mobilização de movimentos populares que defendiam a saúde como direito de todos e dever do Estado. Estabelecido constitucionalmente pela Constituição Federal Brasileira de 1988 e normatizado pelas Leis 8080/90 e 8142/90, o SUS surge com o objetivo de atender às necessidades de saúde da população. No entanto, o Sistema apresenta-se como contra-hegêmonico numa sociedade inserida no modo de produção capitalista. 0 objetivo do artigo é propor uma reflexão sobre os limites e potencialidades de construção e efetivação de um sistema de saúde que atenda às necessidades de saúde da população num contexto de conflitos de interesses no âmbito de uma sociedade capitalista. Trata-se de um artigo de reflexão, que utilizou como referencial teórico o materialismo dialético de Karl Marx. Observou-se que - SUS enfrenta como principal obstáculo para sua consolidação os fortes interesses econômicos no âmbito de uma sociedade onde o lucro e a acumulação de capital são preponderantes e seu fortalecimento passa pela participação de trabalhadores de saúde e, principalmente, usuários na sua defesa.
\end{abstract}

Descritores: Assistência à saúde; Sistema Único de Saúde; Saúde Pública.

\section{The brazilian unified health system: in search for an identity}

\begin{abstract}
Created at the height of transition between the end of military dictatorship and the beginning of restoration democratic rules' law process, the Unified Health System (SUS) emerges as a popular victory, which was as embryo of the Health Reform Movement and the mobilization of popular movements that defended health as a right for all people and as an obligation of the State. Constitutionally established by the 1988 Constitution Brazilian and regulated by the 8080/90 and 8142/90 Laws, SUS emerges with the object to meet the population's health needs. However, the system presents itself as a counter-hegemonic in one society inserted into the capitalist production mode. The aim of this paper is to propose a reflection on the limits and possibilities of construction and execution of a health care system that meets the health needs of the population in the context of conflicts of interest within a capitalist society. It is an article of reflection, which used as a theoretical dialectical materialism of Karl Marx. It was observed that the NHS faces as their main obstacle to consolidating the strong economic interests in the context of a society where profit and capital accumulation are predominant and their empowerment requires the involvement of health workers, and especially users in their defense.
\end{abstract}

Descriptors: Delivery of Health Care; Unified Health System; Public Health.

\footnotetext{
${ }^{1}$ Mestre em Enfermagem pela Universidade Federal de Santa Maria (UFSM), Santa Maria, RS, Brasil.

${ }^{2}$ Pós doutora em Enfermagem pela Universidade Federal de Santa Catarina (UFSC), Florianópolis, SC, Brasil.
} 


\section{Introdução}

Estabelecido pela Constituição Federal de 1988, o Sistema Único de Saúde representa a prova de criar um sistema de saúde baseado em pressupostos como universalidade, integralidade, descentralização e controle social. Deste modo, fariam dele um construto voltado aos interesses dos usuários e potencialmente prejudicial aos interesses da acumulação capitalista, na medida em que um menor número de usuários necessitaria acessar planos privados de saúde ou utilizar equipamentos de saúde de maior densidade tecnológica, de maior custo, ou seja, o SUS, por esse motivo seria, na sua essência, contraditório.

Dessa forma, parte-se da aceitação dos pressupostos constantes na obra de Karl Marx como subsídio para entender como ocorreu o desenvolvimento do setor saúde dentro de um contexto de luta de classes e conflito de interesses, bem como estes interferem hoje sobre a organização do Sistema Único de Saúde.

A história da sociedade brasileira está permeada por contradições e conflitos de interesses de classes, e nesse contexto, o setor saúde tem adquirido importância como política pública, que ao mesmo tempo em que atua como forma de descompressão social e cooptação de classes populares, serve como instrumento de acumulação capitalista.

Nesse sentido, o Sistema Único de Saúde tem tentado exercer esse duplo e contraditório papel, fato que se evidencia, entre outros, pela forma de financiamento, na medida em que os serviços hospitalares e ambulatoriais de média e alta complexidade são pagos por produção e a Atenção Primária em Saúde, e é financiada com base no quantitativo populacional e na adesão a políticas de saúde estabelecidas pelo Ministério da Saúde.

Esse artigo parte desses pressupostos buscando mostrar a contradição do SUS, que é um Sistema que apresenta em sua essência o direito universal à saúde numa sociedade capitalista, em que as formas de gestão, modelo assistencial e pagamento aos prestadores privados podem ser instrumentos de acumulação de capital. Propõe-se uma reflexão sobre esse contexto, e discutindo a importância do contraponto da participação dos atores com interesse no fortalecimento do SUS na busca de sua consolidação enquanto sistema que atenda aos interesses dos usuários.

Nesse contexto, é importante que se defina o sentido da palavra contradição, que muitas vezes é confundida com oposição, para que possamos também perceber onde se encontra a já referida contradição do SUS.

$\mathrm{Na}$ oposição existem dois termos, cada qual dotado de suas próprias características e de sua própria existência, que se opõem quando, por algum motivo, se encontram. Isso significa que, na oposição podemos tomar os termos separadamente, entender cada um deles, entender por que se oporão se se encontrarem e, sobretudo, podemos perceber que eles existem e se conservam, quer haja ou não haja a oposição. Assim, por exemplo, poderíamos imaginar que os termos "senhor" e "escravos" são opostos, mas isso não nos impede de tomar cada um dos conceitos separadamente, verificar suas características e compreender por que se opõem. ${ }^{1}$

Já em relação à contradição, só existe a relação, isto é, não podemos tomar os termos antagônicos fora dessa relação, pois como assegura o principio, trata-se de tomar os termos ao mesmo tempo e na mesma relação, criados por essa relação e transformados nela e por ela. Só há contradição quando a negação é interna e quando ela for a relação que define uma realidade que é em si mesma dividida num pólo positivo e num polo negativo, pólo este que é o negativo daquele pólo positivo e de nenhum outro. ${ }^{1}$

Assim, temos no modo de produção capitalista dois pólos que se negam a si mesmo: burgueses (proprietário dos meios de produção) e proletários (que detém e vendem a força de trabalho), em que o burguês é o não-proletário e proletário é o não burguês. Ou seja, ao mesmo tempo em que um é a negação de outro, ambos existem apenas nessa relação.

No Manifesto Comunista, Marx e Engels estabelecem que "a história de todas as sociedades que existiram até nossos dias tem sido a história da luta de classes. A nossa época, a época da burguesia, caracteriza-se, contudo, pelo fato de ter simplificado os antagonismos de classes. A sociedade toda se cinde, mais e mais, em dois grandes campos inimigos, em duas grandes classes diretamente confrontadas: burguesia e proletariado. ${ }^{2}$

Essas duas classes antagônicas, em processo de contradição, possuem interesses diametralmente opostos. Enquanto a burguesia visa à acumulação capitalista, por meio da expropriação e exploração da força de trabalho, representada pelo proletariado, por meio da mais-valia, essa visa obter, por meio da venda de sua força de trabalho (uma vez que não possui a propriedade dos meios de produção), mais do que sua simples subsistência, mas sua existência enquanto ser humano.

A contradição no interior do SUS, então, reside no fato de que o atendimento das necessidades de saúde da população 
e a acumulação capitalista são um a negação do outro. Assim, como não é possível ser burguês e proletário ao mês tempo, pelas características intrínsecas de cada um dos elementos, também não pode o SUS atender os dois interesses ao mesmo tempo.

Ou seja, ou o Sistema busca atender aos interesses da população, desencadeando ações de promoção e manutenção da saúde e prevenção de doenças e com isso melhora as condições de saúde da população e diminui a demanda a toda uma gama de produtos e serviços oferecidos pelo "mercado da saúde", ou para manter aquecida essa demanda mantemse a população menos saudável.

O objetivo do artigo é propor uma reflexão sobre os limites e potencialidades de construção e efetivação de um sistema de saúde que atenda às necessidades de saúde da população num contexto de conflitos de interesses no âmbito de uma sociedade capitalista.

\section{Metodologia}

Trata-se de um artigo de reflexão, que utilizou como referencial teórico o materialismo dialético de Karl Marx. Utilizouse de revisão bibliográfica, tendo utilizado o referencial do materialismo histórico e dialético, onde realizou-se uma abordagem reflexiva sobre a contradição que se coloca como essência do próprio sistema.

\section{Discussão}

Incialmente é necessário considerar que o Sistema Único de Saúde está estabelecido no contexto de uma sociedade inserida no modo de produção capitalista e que seu objetivo maior deve ser o de garantir a vida, ajudando a promover, proteger e recuperar a saúde de todos.

Desta forma, entende-se que em função do que foi visto, a saúde é a "mercadoria" oferecida à população brasileira, uma vez que possui valor de uso (na medida em que satisfaz as necessidades do homem) e valor de troca (na medida em que pode comprar outras mercadorias).

Inicialmente, a mercadoria é um objeto que, a partir de suas propriedades materiais, tem a propriedade de satisfazer as necessidades do homem. Essa característica é conhecida como valor de uso. Por outro lado, a mercadoria também tem a propriedade de poder ser trocada por mercadorias distintas de si própria ou, em outras palavras, de comprar outras mercadorias. A essa característica chamou-se valor de troca. Então, a mercadoria pode ser definida como uma riqueza, mercantil, que possui valor de uso e valor de troca, ao mesmo tempo. ${ }^{3}$

Partindo da percepção da saúde vista como mercadoria, é natural que seja colocada à venda no mercado (com grande valor de uso e de troca) e será, com isso, um produto que estará mais acessível àqueles que tiverem capacidade de compra-la. No interior de uma sociedade caracterizada pela extrema desigualdade social e econômica, a saúde, como tantos outros produtos de consumo, seria um privilégio de parte da população, com possibilidade de pagar por ela. Ao mesmo tempo, seria uma fonte de lucro daqueles que põe à venda este "produto", e, como consequência, também um importante meio de acumulação capitalista.

A oposição a essa situação seria, exatamente, a existência de um sistema público de saúde universal, que tivesse entre seus princípios a promoção e manutenção das condições de saúde da população, que logicamente, iria de encontro aos interesses anteriormente citados.

O processo de "venda" do "produto" saúde intensificou-se principalmente a partir da década de 60 do Século XX, com o desenvolvimento do chamado "complexo médico-industrial", conceituado como conjunto interligado de produção de bens e serviços em saúde que se movem no contexto da dinâmica capitalista. ${ }^{4}$

Dessa forma, a produção e venda do produto saúde ocorrem dentro de uma lógica de mercado, onde o acesso às ações de serviços de saúde estão disponível com maior facilidade àqueles que podem pagar por eles, e a organização dos serviços de saúde seguiria a lógica deste mesmo mercado, que por si só regularia o setor saúde, por meio dos mecanismos de demanda e oferta.

A ideologia liberal, também em relação à prática médica, apresenta o mercado como capaz de assegurar os interesses dos produtores e dos consumidores, ainda que o discurso médico liberal procure atenuar e até mesmo descaracterizar as 
evidências dessa identidade de funcionamento. Nesse caso, o melhor gerente do sistema de saúde seria uma entidade abstrata, mas concretamente ubíqua nos países que experimentaram um desenvolvimento capitalista - 0 próprio mercado. ${ }^{5}$

Como entender, então, que um sistema de saúde como o SUS, que tem com princípios a universalidade, a integralidade e o controle social, tenha nascido no âmbito de uma sociedade capitalista, e, ainda mais, num momento histórico da hegemonia do pensamento econômico neoliberal? "De uma perspectiva processual: como o SUS foi possível? No Brasil? E ainda no tempo áureo do neoliberalismo?" Sim, porque o SUS tem a marca genética do intervencionismo estatal sobre a dinâmica do mercado. É primo-irmão dos sistemas socializados de saúde e sobrinho do estado de bem-estar social. ${ }^{6}$

É importante observar ainda o fato que o Sistema Único de Saúde nasce num contexto de hegemonia da ideologia neoliberal, em que havia uma tendência comum a todos os países da América Latina no sentido da privatização da saúde. As diferentes modalidades de privatização teriam como denominador comum a transformação da saúde de um direito de cidadania em uma mercadoria e derivariam de uma dupla necessidade: favorecer as políticas de ajuste e impulsionar a mercantilização dos setores rentáveis dos serviços de atenção à saúde. ${ }^{7}$

Fazendo-se uma extrapolação do contexto político e econômico brasileiro e latino-americano à época para o contexto mundial prevalecente, deduz-se também pela existência de vários e importantes obstáculos à efetiva implantação do SUS.

Nesse sentindo, o contexto político nacional e internacional de implantação do SUS não se mostrou favorável. A configuração conservadora dos governos que se sucederam no período da transição democrática estava em perfeita sintonia com o ambiente internacional, marcado pela rediscussão do papel do Estado, e se traduzia em propostas de novos modelos de políticas sociais. A partir do questionamento da universalização de direitos, proliferaram propostas de focalização do gasto público nos setores mais pobres da população, deixando para o mercado a produção de serviços sociais destinados aos setores mais favorecidos. ${ }^{7}$

Partindo do pressuposto de que o SUS trata-se de um sistema público de saúde, é importante considerar as formas pelas quais podem ocorrer sua gestão e financiamento.

Desse ponto de vista pode-se afirmar que esses sistemas se organizam a partir dessas duas vertentes: a de um sistema público de saúde complementado pelo privado-filantrópico (que atua de forma complementar) e a provisão de serviços de saúde baseado na livre concorrência de prestadores privados de saúde. Como não poderia de deixar de ser, cada uma dessas vertentes leva a que os serviços se estruturem e funcione de forma diversa, o mesmo ocorrendo com o financiamento.

No que se refere à gestão segundo os interesses coletivos, sua prática administrativa se confunde com a organização da produção de serviços de saúde voltada para as necessidades sanitárias de uma coletividade. Essa modalidade de gestão prioriza a realização de diagnósticos coletivos de saúde e adota uma postura de parceria constante entre o saber técnico e os interesses sociais e a consciência sanitária dos cidadãos. ${ }^{8}$

O SUS nasce, enquanto princípios e diretrizes, baseado nas idéias consolidadas no relatório final de VIII Conferencia Nacional de Saúde (1986), que por sua vez teve como substrato idéias defendidas pelo Movimento da Reforma Sanitária. Processo esse ocorrido no contexto no ocaso do regime militar e de retomada da participação popular na discussão dos grandes temas nacionais onde se inclui, obviamente, o setor saúde e onde uma das bandeiras de luta era: saúde é democracia, democracia é saúde.

Os princípios constitucionais do SUS parecem caminhar no sentido de um sistema de saúde identificado com a democracia participativa e com os interesses e necessidades da população brasileira, especialmente das classes populares. A legislação infraconstitucional que vem a seguir com o objetivo de regulamentar os dispositivos constitucionais (Leis 8080/90 e 8142/90) pareciam caminhar na mesma direção.

No entanto, algumas questões precisam ser mais bem analisadas. A primeira delas é o reconhecimento, por meio da própria legislação, de que o Sistema Único de Saúde não é tão "único" assim, na medida em que o próprio Ministério da Saúde, por meio da Agência Nacional de Saúde (ANS) passa a regular os planos privados de saúde. Ora, na medida em que passa a regular, obviamente, passa a reconhecer a existência de um sistema privado e de um sistema público.

Um deles, o SUS, fundamentado na concepção do direito à saúde - portanto de caráter universal e igualitário; 0 outro baseado na lógica do mercado em que a participação é desigual, embora formalmente livre, sendo os planos de saúde vistos como produtos a serem registrados e controlados quanto à qualidade e ao preço. Nesse sentido, a política regulatória tem como consequência a fragilização do projeto do SUS do ponto de vista político-ideológico, além de reforçar as crenças cognitivas a respeito dos dois sistemas. ${ }^{9}$ 
A prevalência dessa dualidade passa a percepção de que a legislação constitucional reconhece a existência de um sistema privado, com base nas leis de mercado, destinado à camada da população com maior poderio de consumo (inclusive de saúde, que é afinal uma mercadoria) e um sistema público, que apesar de universal, está, na verdade, destino a populações com capacidade de consumo mais limitado, mas que, ao mesmo tempo, está destinado a fortalecer a rede privada de produtos e serviços de saúde.

Na continuação do processo de descentralização do SUS, rumo à municipalização da gestão e da execução das ações e serviços de saúde, foram necessárias normas que definissem critérios para que esse processo ocorresse, definindo, entre outros, forma de financiamento das ações e serviços de saúde critérios para o repasse de recursos financeiros aos municípios e atribuições e responsabilidades a serem assumidas pelos diferentes entes federativos.

Assim, foram editadas as Normas Operacionais Básicas 91, 92 e 93, que não produziram modificações importantes na forma de financiamento do SUS, baseado no pagamento por produção realizada, tanto para municípios como para prestadores privados. Como exceção nesse processo, a NOB 01/93 abre a possibilidade de repasse de maior autonomia dos municípios, quando assumem a forma de gestão denominada "semi-plena". Essa, diz respeito a uma situação mais avançada, com descentralização da gestão financeira, através da transferência direta e automática dos recursos federais (teto financeiro), para assunção pela direção municipal do SUS da totalidade das responsabilidades gerenciais e do reordenamento do modelo assistencial. ${ }^{10}$

No entanto, é principalmente a partir da Norma Operacional Básica (NOB) 01/96 que fica caracterizada a idéia de um sistema de saúde que tem por objetivo a atender interesses conflitantes, ou seja, de um lado, atender ao interesse da acumulação capitalista, e de outro, como já referido, aos interesses e necessidades da população.

Esta NOB traz como uma das novidades uma nova forma de remuneração da assistência ambulatorial: a atenção Básica que seria financiada pelo PAB-Piso Assistencial Básico (fixo e variável) que seria calculado através de uma per capta fixo (PAB fixo) ou de acordo com a adesão a alguns programas definidos pelo Ministério da Saúde (PAB variável). Os procedimentos de média e alta complexidade, bem como a assistência hospitalar, (em sua grande maioria procedimentos realizados por prestadores privados) continuaram sendo pagos por procedimentos, cada um com um valor previamente definido por meio de um valor estabelecido, em tabela de procedimentos, pelo Ministério da Saúde.

A Portaria GM/MS 2.203 de 06 de novembro de 2006, que institui a NOB-SUS 96 estabelece uma hierarquização em relação à produção ambulatorial, estabelecendo a existência de procedimentos de Atenção Básica, de média e alta complexidade. Os primeiros passaram a não ter valor de pagamento, sendo as ações de Atenção Básica financiadas por um valor fixo (Piso Assistencial Básico), calculado por meio de um valor per capta populacional e um valor variável, de acordo com a adesão a determinados programas estabelecidos pelo Ministério da Saúde. ${ }^{11}$

Ao contrário da Atenção Básica, os procedimentos ambulatoriais de média e alta complexidade são pagos por procedimentos. A remuneração por serviços produzidos consiste no pagamento direto aos prestadores estatais ou privados contratados e conveniados, contra apresentação de faturas, referentes a serviços realizados conforme programação e mediante prévia autorização do gestor, segundo valores fixados em tabelas editadas pelo órgão competente do Ministério (Setor de Assistência Social/Ministério da Saúde). ${ }^{11}$

Como consequência desta forma de pagamento dos prestadores de serviço ao SUS, o dinheiro público compra hoje serviços hospitalares e de apoio diagnóstico e terapêutico de alta complexidade de um setor privado que foi estruturado na grande maioria das vezes com financiamento a fundo perdido pelo próprio dinheiro público: situação perversa e de difícil reversão no cenário atual e de solução com investimentos no setor público a médio e longo prazo. ${ }^{12}$

Esta forma de pagamento nos parece uma forma de conciliar interesses diversos, na medida em que aumenta a cobertura e 0 acesso da população aos serviços básicos de saúde, obtendo assim, legitimação e aprovação popular ao Sistema Único de Saúde, ao mesmo tempo em que continua aberta a perspectiva de acumulação capitalista por meio do pagamento de procedimentos por produção, ou seja, quanto maior o número de procedimentos realizados, maior 0 volume de recursos financeiros recebidos.

Aqui está a grande contradição e ao mesmo tempo o grande obstáculo à consolidação do SUS como um sistema que atenda realmente às necessidades de saúde da população brasileira.

A conferência de Alma Ata, em 1978, estabeleceu o consenso de que a Atenção Primária seria a estratégia fundamental e a porta de entrada do sistema de saúde com capacidade para resolver $80 \%$ dos problemas de saúde da população. Estratégias que fortalecem a capacidade da atenção primária e que enfatizam a promoção da saúde tendem a melhorar o status de saúde e reduzir custos. ${ }^{13}$ 
Na medida em que a Atenção Primária em Saúde tem o potencial de resolução citado, impacta sobre a demanda aos serviços hospitalares e ambulatoriais de média e alta complexidade, e por consequência nos recursos financeiros recebidos por esses prestadores (filantrópicos ou não).

Partindo-se dos pressupostos aqui apresentados, é necessário revisar a forma de financiamento aos prestadores de serviços de saúde, se o que se deseja é estabelecer a premissa de que o SUS está posto como um Sistema, que tem como interesse maior a defesa dos interesses de saúde da população.

Outro aspecto a ser considerado em relação à oferta de ações e serviços de saúde na órbita da iniciativa privada é a forma como se dá sua inserção no Sistema. A inclusão de ações e serviços de saúde no SUS deve ocorrer tendo como critério as necessidades da população, ou seja, o SUS deve contratar serviços que a população realmente necessita, definida essa necessidade por meio de critérios eminentemente técnicos.

No entanto, o que acontece muitas vezes é que a oferta de serviços atende mais as necessidades dos prestadores privados de saúde mais do que aos usuários do SUS, mesmo que tenha ocorrido financiamento de equipamentos com recursos públicos. Dessa forma corre-se o risco de haver uma oferta maior do que a necessidade em alguns serviços e saúde e uma demanda maior do que a oferta em outros. O fator determinante para uma ou outra situação é a remuneração do serviço a ser ofertado, ou seja, há o predomínio do fator econômico sobre o fator epidemiológico.

Um exemplo de situações como essas ocorrem quando emendas parlamentares determinam o repasse de recursos públicos para a aquisição de equipamentos para prestadores privados sem que haja uma discussão e/ou estudo técnico preliminar que determine a necessidade da oferta do serviço que será gerado pelo equipamento financiado. É necessário que a destinação de tais recursos tenha como critério para repasse uma análise técnica para o atendimento das reais necessidades sanitárias dos usuários do SUS.

Além dos prestadores de serviços ao SUS, também não se pode menosprezar a importância e poderio econômico de outros setores que tem na doença uma importante, e talvez principal, fonte de lucro, como, por exemplo, a indústria farmacêutica e o complexo médico-industrial. É evidente que a existência de uma população mais saudável, que é aquilo que busca, em última análise, o Sistema Único de Saúde teria impacto financeiro direto sobre esses setores, diminuindo seus ganhos e lucros.

No que se refere à questão da legitimação, é fundamental o papel dos usuários no controle social, pois na medida em que têm papel decisório importante, de caráter deliberativo e fiscalizatório, inclusive respaldados constitucionalmente e pelas Leis 8080/90 e 8142/90, atuam como atores nesse processo.

Neste sentido, a própria população, por meio de seus representantes nos órgão de participação popular (conferencias e conselhos) podem legitimar a acumulação capitalista dos setores ligados à área da saúde, na medida em que abram mão dos direitos que the são assegurados ou que avalizem propostas que favoreçam os setores que buscam a maximização do lucro no mercado da saúde.

Alguns questionamentos interessantes em relação a um sistema que tem como embrião a mobilização da sociedade e cuja forma de organização encontra respaldo na Lei Maior e na legislação infraconstitucional são: Por que as entidades sindicais, mesmo as mais organizadas e politizadas, apesar de todas as declarações de apreço ao SUS, aspiram, no seu cotidiano, à inclusão de seus filiados em alguma das modalidades da medicina de mercado? Por que, via de regra, os movimentos de trabalhadores de saúde mantém-se, ou apáticos e frustrados, ou aderem a lutas onde o imediatismo corporativo só é comparável ao seu ressentimento e a uma espécie de mágoa sem causa precisa? Por que, apesar das boas intenções, a maioria dos governos populares democráticos ou progressistas, não puderam alterar as relações dos usuários e dos trabalhadores com as Instituições Públicas, criando novos padrões de expectativas e novos projetos? ${ }^{14}$

A adolescência - e o SUS é exatamente isso - é caracterizada como uma etapa de transição, ao fim do qual se consolida sua identidade própria, com concepções, valores, e subjetividades em geral, construídos ao longo desse processo, baseado no vivido e nas diferentes relações estabelecidas desde a infância, na família até o final desse período.

A mesma ideia pode ser aplicada ao Sistema Único de Saúde (SUS), que se encontra em um momento de definir sua identidade e aos interesses ao quais serve: à acumulação do capital ou às necessidades de saúde (e não da doença) da população. Esta situação caracteriza a contradição do SUS, na medida em que não é possível, da mesma forma que na relação burguesia-proletariado, servir aos interesses de ambos os atores ao mesmo tempo. 


\section{Considerações finais}

Esta reflexão confirma que a forma como o SUS está estruturado, faz com que tenhamos hoje um Sistema que ainda não conseguiu responder às demandas da população e melhorar suas condições de saúde. Que apresenta deficiências importantes principalmente no campo da assistência, que é apenas a face mais visível do Sistema e que se presta de forma mais acentuada à espetacularização por parte de uma mídia comprometida com os interesses da acumulação capitalista.

Uma das questões que está no centro da contradição ora exposta e que coloca a assistência à saúde como centro das dificuldades do SUS é a remuneração dos procedimentos de maior densidade tecnológica, que é uma questão crucial no SUS, e está numa fase inicial de resolução (com o pagamento por valor global de alguns prestadores de serviço).É imprescindível que os atores sociais envolvidos com a defesa dos interesses dos usuários aprofundem a discussão visando o empoderamento em relação a esse tema, visando fortalecer o SUS como patrimônio da população brasileira.

A partir do momento em que há o entendimento de que cabe a um sistema público de saúde priorizar o atendimento das necessidades da população, defendemos a ideia de que é necessário que todos os atores envolvidos com o setor da saúde (principalmente trabalhadores em saúde e usuários) retomem o processo de mobilização em sua defesa, mobilização essa que está na própria gênese do SUS.

Acredita-se que sem uma ampla mobilização e aprofundamento das discussões sobre o papel do SUS na sociedade brasileira por parte dos atores envolvidos, o Sistema estará cada vez mais a serviço da classe capitalista e da acumulação de capital.

\section{Referências bibliográficas}

1. Chauí MS. O que é Ideologia. $2^{\mathrm{a}}$ ed. São Paulo: Brasiliense; 2001.

2. Marx K, Engels F. Dossiê Manifesto Comunista. [Citado em 6 mai 2012]. Disponível em: http://www.scielo.br/pdf/eal v12n34/v12n34a02.pdf

3. Carcanholo MD. A importância da categoria valor de uso na teoria de Marx. Pesquisa e Debate. 1998; 9(14):17-43.

4.Andreazzi MFS, Kornis GE. Padrões deAcumulação Setorial: Finanças e Serviços nas Transformações Contemporâneas da Saúde. Ciência \& Saúde Coletiva. 2008;13(5):1409-1420.

5. Campos GW, Merhy EE, Nunes ED. Planejamento Sem Normas. 2aed. São Paulo: Editora HUCITEC; 1994.

6. Campos GW. Gestão Pública Relação Público Privado na Saúde. In Santos NR, Amrante PD (Org.). Gestão Pública e Relação Público Privado na Saúde. Rio de Janeiro: Cebes; 2010.

7. Menicucci TMG. Implementação da Reforma Sanitária: a formação de uma política. Saúde e Sociedade. 2006; 15(2):72-87.

8. Mendes A, Marques RM. Sobre a Economia da Saúde: campos de avanço e sua contribuição para a gestão da saúde pública no Brasil. [Citado em 15 nov 2011]. Disponível em: http://portal.saude.gov.br/portal/arquivos/pdf/sobre_econ_ saude.pdf

9. Menicucci TMG. A Reforma Sanitária Brasileira e as Relações entre o Público e o Privado. In: Santos NR, Amrante PD (Org.). Gestão Pública e Relação Público Privado na Saúde. Rio de Janeiro: Cebes; 2010.

10. Lucchese PTR. A Gestão Semiplena no Sistema Único de Saúde e a NOB SUS 01/96. [Citado em 07 nov 2011]. Disponivel em: http://www.datasus.gov.br/cns/temas/NOB96/gest\%C3\%A3osemiplenapat.htm

11. Brasil. Portaria GM/MS 2.203 de 06 de novembro de 2006. [online]. 2006 [Citado em 14 abr 2012]. Disponível em: http://bvsms.saude.gov.br/bvs/saudelegis/gm/1996/prt2203_05_11_1996.html

12. Bueno WS, Merhy EE. Os Equívocos da NOB 96: Uma Proposta em Sintonia com os Projetos Neoliberalizantes? In: Conferencia de Saúde online. [Citado em 10 dez 2011]. Disponível em: http://www.datasus.gov.br/cns/temas/NOB96/ NOB96crit.htm

13. Onoko-Campos, Campos GWS, Ferrer AL, Corrêa CRS, Madureira PR, Gama CAP, et al. Avaliação de estratégias inovadoras na organização da Atenção Primária à Saúde. Rev Saúde Pública. 2012; 46(1):43-50.

14. Campos GW. Sobre a Peleja dos Sujeitos da Reforma, ou da Reforma dos Sujeitos em Peleja. Saúde e Sociedade.1992;1(2) 79-95. 


\section{Sérgio Arthur Silva}

Endereço para correspondência - Rua André Marques, 675. Bairro Centro, CEP: 97015-140, Santa Maria, RS, Brasil E-mail: sergio-silva@saude.rs.gov.br

Lattes: http://lattes.cnpq.br/6676073546395649

Bruna Parnov Machado - brunaparnovmachado@yahoo.com.br

Suzinara Beatriz Soares Lima - suzibslima@yahoo.com.br

Enviado em 23 de maio de 2012.

Publicado em 28 de novembro de 2013. 